\title{
Some Important Criteria for Presentation and Analysis of Data Obtained from Fermentation Processes
}

\section{Nelson Pérez Guerra*}

Department of Analytical and Food Chemistry, Food Science and Technology Faculty, University of Vigo, Ourense Campus, 32004 Ourense, Spain

\section{Introduction}

Open access provides unrestricted access via the Internet to peerreviewed research articles dealing with different research areas. In the fermentation field, this initiative could be an effective way for a fast dissemination of the growing number of researches related with the biotechnological production of different value added products. The OMICS offers various features including digital articles, audio listening, language translation and social networking (Face book, Twitter, Linked in, RSS Feeds), which allow the virtual communication and the rapid information exchange between worldwide researchers. This information is very useful for many academic readers and researchers, who develop their work to improve existing fermentation procedures or to design new reproducible processes with potential industrial implementation.

To contribute with this development, the articles dealing with fermentation processes and submitted for publication in any Open access journal (e.g. Fermentation Technology) must be well written with a clear language without ambiguities, and with an adequate presentation, accurate analyses and complete discussion of the data. This improves the quality of the published scientific papers and enables their better understanding.

For these reasons, the present editorial attempts to provide a general guide to present, analyse and interpret correctly the results obtained in fermentation processes, which may be useful for students and researchers that publish research articles in this field.

\section{Presentation of Experimental Data and Statistical Analysis of the Results}

\section{Comparison of data}

The statistical methods used to compare data (e.g. means concentrations of biomass and products) must be clearly and completely described in the "Materials and Methods" section. Information about the number of replicates and runs (repetitions) made in each analytical determinations must also be provided. Data may be presented in tables as means with their standard deviations (SD) in parenthesis beside them. In addition, the results of the statistical analysis (e.g. comparison of means) with the corresponding signification level must be presented with the data in the tables.

\section{Studies on the effects of key factors on response variables}

The effects of independent factors (e.g. initial level of $\mathrm{pH}$, nutrients, temperature) on different response variables (e.g. biomass formation or product synthesis) could be preferably carried out by using factorial designs rather than using "one variable at a time" method. The latter method is time consuming and could lead to an incomplete interpretation of the behaviour of the system, resulting in lack of predictive ability, mainly when there are interactions between the independent factors. In contrast, the use of factorial designs allows to reduce the number of experiments and to obtain empirical mathematical models describing the effect of each independent factor (both linear and quadratic) and their interactions on the response variables. The analysis of variance of the empirical models obtained and the value of the regression coefficient must be presented in a table. The statistically significant coefficients of the independent variables and their interactions (as values \pm standard errors) and the significance level (commonly $P<0.05$ ) used must also be indicated in a table. After obtaining the optimal values for the independent factors that maximize the levels of the response variables, a verification of the predicted results in the optimal conditions must be carried out in duplicate or triplicate incubation experiments.

However, it could be taken into account that the results obtained from complete factorial designs with more than three factors could be of difficult interpretation when the number of significant coefficients for the factors and their interactions are high [1]

\section{Modelling the time course of kinetic variables}

The time course of key variables in a fermentation process must be clearly presented in graphics, with distinguishable symbols representing the mean values of the variable with the corresponding error bars on each graphed experimental point. In addition, the number of replicates and runs must also be clearly indicated in the figure caption.

The experimental data collected in a dynamic process like microbial growth of metabolite production at different sampling times are a set of discrete points and they must be shown in the figures as single points that should not be connected with a straight line [2]. This is because these points have some experimental error in them that could describe an erratic behaviour in the dynamic of the data. In these cases, a mathematical model should be used to smooth the experimental data and describe the trend observed in them. The predictions of the model are continuous and must be plotted as continuous lines. With this approach, the values of different parameters (e.g. the rates, efficiencies or yields) can be reasonably calculated from the predicted values of some measured variables (concentrations of nutrients and products).

The most common criterion used to evaluate the goodness of fit of a mathematical model to data is the coefficient of determination $\left(R^{2}\right)$. However, when a set of models are compared, the use of this coefficient is not always sufficient to determine which model produces the best fit. In these cases, it is convenient to use other criteria such as the values

*Corresponding author: Dr. Nelson Pérez Guerra, Food Science and Technology Faculty, University of Vigo, Ourense Campus, 32004 Ourense, Spain, Tel: +34-988-387062; Fax: +34-988-387001; E-mail: nelsonpg@uvigo.es

Received May 14 2012; Accepted May 15, 2012; Published May 17, 2012

Citation: Guerra NP (2012) Some Important Criteria for Presentation and Analysis of Data Obtained from Fermentation Processes. Ferment Technol 1:e114. doi:10.4172/2167-7972.1000e114

Copyright: (c) 2012 Guerra NP. This is an open-access article distributed unde the terms of the Creative Commons Attribution License, which permits unrestricted use, distribution, and reproduction in any medium, provided the original author and source are credited. 
Citation: Guerra NP (2012) Some Important Criteria for Presentation and Analysis of Data Obtained from Fermentation Processes. Ferment Technol 1:e114. doi:10.4172/2167-7972.1000e114

Page 2 of 2

of the sum of the squared errors (SSE), the mean relative percentage deviation modulus (RPDM) and the standard error of estimate (SEE) of each model to judge best fit [3].

After performing an accurate and complete analysis of the results and extracting the appropriate supported conclusions, the results obtained must be compared with those obtained by other researchers in similar studies. In this case, speculative interpretations of the results and/or the abusive use of references to increase the length of the article should be avoided.

Well-presented research articles submitted to Fermentation Technology will improve the scientific quality of this Journal.

\section{References}

1. Robinson PH, Wiseman J, Udén P, Mateos G (2006) Some experimental design and statistical criteria for analysis of studies in manuscripts submitted for consideration for publication. Animal Feed Science and Technology 129: 1-11.

2. Durbin CG Jr (2004) Effective use of tables and figures in abstracts, presentations, and papers. Respir Care 49: 1233-1237.

3. Guerra NP, Catro LP (2012) Modelling the effects of ageing time of starch on the enzymatic activity of three amylolytic enzymes. The Scientific World Journal $1-13$. 